K. Meyer $\cdot$ S. Niemann $\cdot$ T. Abel

\title{
Gender differences in physical activity and fitness-association with self-reported health and health-relevant attitudes in a middle-aged Swiss urban population
}

Received: 12 January 2004 / Accepted: 27 April 2004 / Published online: 15 June 2004

(C) Springer-Verlag 2004

\begin{abstract}
In Switzerland lack of exercise is common. To improve physical exercise in both women and men, campaigns should consider the motivation for physical activity with respect to gender. This study explores the patterns of self-reported sport activity, habitual physical activity and physical fitness, and associated indicators of self-reported health, health-relevant attitudes, and resources in an urban Swiss population. Using the Bern Lifestyle Panel questionnaire, 511 women and 413 men, aged 55-65 years, in the German-speaking capital of Switzerland were assessed. From the three surveys carried out from 1996 to 1998, this study used the data from the 1997 survey for a cross-sectional analysis. Women demonstrated a lower prevalence of sport activity than men but a higher prevalence of habitual physical activity. Forty-six percent of the women but $80 \%$ of the men reported a high level of fitness. In the logistic regression analysis, sport activity in the women was significantly associated with indicators of health, health-relevant attitudes such as internal and external health locus of control, and social class. Among the men, no association with health-relevant orientation could be found. The probability of habitual physical activity among the women was associated with perceived good health, health-relevant orientation and social class, while related factors among the men were indicators of health. In both women and men, perceived good health was strongly associated with self-reported physical fitness. Additionally, women's fitness was related to perceived disease-related limitation
\end{abstract}

\author{
K. Meyer $(\bowtie)$ \\ Swiss Health Observatory, Neuchâtel, \\ University of Bern, Espace de l'Europe, \\ 2010 Neuchâtel, Switzerland \\ e-mail: katharina.e.meyer@freesurf.ch \\ Tel.: +41-32-7136536 \\ Fax: +41-32-7136654 \\ S. Niemann · T. Abel \\ Institute for Social and Preventive Medicine, \\ Unit for Health Research, \\ University of Bern, \\ Bern, Switzerland
}

and indicators of health status. The findings indicate a gender-specific distribution of sport activity, habitual physical activity and fitness. Compared to men, physical activity in women is associated more with health-relevant orientation. Along with indicators of health, attention should be paid to both female and male perception of health and self-reported attitudes when there is an attempt to improve physical activity. Since self-reported health status, disease-related limitations, and habitual physical activity, among others, are strongly affected by sociocultural and structural influences, caution should be kept in drawing general conclusions from the findings.

Keywords Physical activity and gender - Self-reported physical fitness $\cdot$ Health promotion

\section{Introduction}

Sport and physical exercise are associated with health status, either directly by physiological adaptation or indirectly via other health-relevant behavior and attitudes of a population. There is empirical evidence that the individual perception of good health is significantly related to a good functional health status (Idler and Benyamin 1997), and the perception of health status is a significant resource in terms of duration and intensity of sport activity (Abel et al. 1998). Additionally, in developed countries ways of being physically active seem to be determined by the individual's motivation to perform physical activity; that means physical activity on the grounds of expediency and/or mindset (Cockerham et al. 1993). Little is known about the patterns of association between physical activity, indicators of perceived health status and health-relevant attitudes (e.g., being responsible for one's own health in the sense of a high internal health locus of control; Wallston and Wallston 1993) in women, and whether here gender differences exist. Physiologically, physical activity and fitness are related. In the concept of salutogenesis, self-reported fitness is 
postulated as a resource for an adequate mastery of life (Knoll 1997; Woll 1996).

In the present study, two questions were addressed using a representative urban sample of Swiss women and men aged 55-65:

1. Are there significant gender differences in the distribution of patterns of sport activity, habitual physical activity and fitness?

2. In women, are different levels of self-reported sport activity, habitual physical activity and fitness associated with indicators of self-reported health, healthrelevant attitudes and resources? Do the patterns of association differ from those in men?

The findings may contribute to a better understanding of gender-specific behavior in self-reported physical activity, and differences in fitness in a middle-aged population, which is important for the promotion of physical activity.

\section{Subjects and methods}

Sampling

The present cross-sectional study was based on data from the Bern Lifestyle Panel (BLP), a survey of healthy lifestyles and their determinants. The sample was selected at random from the City of Bern resident population register. From the three surveys carried out in 1996, 1997 and 1998, our analysis used data from the 1997 survey. The sample consisted of 511 females (55.3) and 413 males $(44.7 \%)$ between the ages of 55 and $65(n=924 ; 83 \%$ of the initial sample surveyed 1996). Data were collected using computer-assisted telephone interviewing. The questionnaire consisted of indicators of self-reported health and lifestyle, including health-relevant attitudes and behavior, and psychosocial resources (for details, see Abel et al. 1999).

\section{Variables}

Items were taken from the BLP code book to establish variables, which were applied as follows:

\section{Sport:}

Information on the number of hours per week spent on regular sport and exercise was used to establish the sport activity variable, coded as none $=0, \leq 2 \mathrm{~h} /$ week $=1$, and $\geq 3 \mathrm{~h} /$ week $=2$.

Habitual physical activity:

The habitual physical activity variable was established using dichotomous information on (a) going for a daily walk and (b) $\geq 20 \mathrm{~min} /$ day walking or (c) cycling to work or to go shopping. The codes used were none $=1$, moderate ( $\mathrm{a}$ and $\mathrm{b}$ or $\mathrm{c}$ ) $=2$ and much activity ( $\mathrm{a}$ and $\mathrm{b}$ plus c) $=3$.
Physical fitness:

Physical fitness is understood as self-reported functional status as experienced in daily activities. Fitness was assessed using a 12-item short form of the FFBMOT questionnaire (Bös et al. 2002). The fitness variable was established by calculating a total score for the 12 items and was categorized as high fitness (slight and/or no problems with carrying out the tasks required) $=1$; moderate fitness (moderate problems with carrying out the tasks required) $=2$; low fitness (not able to carry out, and/or great problems with carrying out the tasks required) $=3$.

Perceived health status:

This was assessed using two questions: (a) "In general, would you say your health is .......?" (perceived bad and/or very bad health $=1$; perceived moderate health $=2$; perceived very good and/or good health $=3$ ) (McDowell and Newell 1996); (b) "Over the last 12 months, have you felt limited by health problems in meeting your daily tasks?" (Bury 1981) (greatly and/or very greatly limited $=1$; moderately limited $=2$; little and/or not at all limited=3).

Indicators of self-reported health:

Body mass index (BMI) $(<26 ; 27-30 ; \geq 31)$. Number of diagnoses during lifetime (total score) (none $=1$; $1=2 ; \geq 2=3$ ) (Haapanen et al. 1997). Self-treatment using pharmaceutical products (none and $1=1 ; \geq 2=2$ ). Total score of medication (sum of all 11 medication items) (none $=1 ; 1=2 ; \geq 2=3$ ). Use of a home remedy (frequently $=1$; sometimes $=2$; seldom or never $=3$ ).

Health-relevant attitudes:

Health locus of control (HLC internal; external, related to both fate and medical systems (Lüschen et al. 1995). For each subscale, the arithmetic mean was calculated for categorization as follows: a mean value of 1 or 2 corresponded to low control, a mean of 3 to moderate control, and a mean of 4 or 5 to high control. Sense of coherence (SOC) (Abel et al. 2000b): for an individual, a total score was calculated (sum of 13 items divided by 13) ( $>1$ SD below mean=low SOC), $\leq 1$ SD below mean=moderate SOC; $>1$ SD above mean=high SOC).

Sociodemographic variables:

British Social Class (BSC): professionals=BSC I; intermediate $=\mathrm{BSC}$ II; skilled (nonmanual) $=\mathrm{BSC}$ IIIN; skilled (manual)=BSC IIIM; semiskilled and unskilled=BSC IV/V. Housewives were classified according to their husband's profession.

Education:

Seven hierarchical categories from primary school (1) to university level (7) were subsumed under three groups: low $($ Sek I $)=1$, intermediate $($ Sek II $)=2$, and high educational level (tertiary) $=3$.

Marital status:

Unmarried, married, widowed, divorced.

Variables were categorized with respect to (a) a categorization proved applicable in previous studies (Abel et 
al. 2000a, 2001), and (b) a meaning, which makes sense in the context of the questions of the present study.

\section{Data analysis}

Data were analyzed using the SPSS program (Version 10.0). In a first step, the distribution of all categorized variables was compared for women and men. The Pearson chi square value and two-sided significance value were calculated using the chi square test. Subsequently, simple correspondence analyses were performed separately for women and men to provide a graphical representation of the statistical association between the sport activity, habitual physical activity and fitness variables, and the other health-relevant indicators to be assessed. Based on the results, sport activity, habitual physical activity, and fitness were dichotomized ("no" vs "moderate" or "much") for logistic regression analyses, and used as dependent variables. Regression models were fitted to reveal those variables, which provided the most plausible answer, and the greatest net effect of variance explanation for the dependent variables. The odds ratio, $95 \%$ confidence interval, and Nagelkerkes Pseudo $\mathrm{R}^{2}$ were calculated.

\section{Results}

Frequency distribution of variables in women and men

Table 1 presents an overview of all variables. Women reported doing either no or just moderate sport activity, and less frequently doing much sport more frequently than men. Among women, the percentage of no habitual physical activity was lower, while the prevalence of either moderate or much habitual physical activity was higher than in the men. More women than men reported that they were either unfit or moderately fit, while more men than women reported that they were very fit. Compared to men, the prevalence of perceived good health was lower, and perceived moderate disease-related limitation was higher in the women. Significant gender differences could be demonstrated for most of the indicators on self-reported health status, and health-relevant attitudes, with the exception of external HLC (fate).

Logistic regression of sport activity, habitual physical activity and physical fitness

Tables 2 and 3 show results of the regression of sport activity, habitual physical activity, and fitness as a function of health relevant indicators.

\section{Sport activity:}

In women with a $\mathrm{BMI} \leq 26$, the probability of regular sport was greater than in women with a BMI $\geq 31$ (Table 2). The same was true for women who frequently used home remedies compared to those who seldom did. In women with low internal HLC, the frequency of sport activity was lower than in women with high internal HLC. In contrast, among women with low external HLC (fate) the likelihood of sport activity was much than among women with high external HLC. Both women in intermediate jobs (BSC II) and female skilled manual workers (BSC IIIM) were less likely to do sport compared to female professionals (BSC I). In men with a $\mathrm{BMI} \leq 26$, the likelihood of sport activity was higher than among those with a $\mathrm{BMI} \geq 31$ (Table 3). Compared to men with a high educational level, those with compulsory schooling were less likely to practice a sport. Prediction of the variance of sports was marginal.

Habitual physical activity:

The probability of practicing habitual physical exercise was higher among women with perceived good health than among those with perceived poor health (Table 2). Women with low internal HLC, and external HLC (belief in the medical system) demonstrated lower ORs than women with high internal and external HLC. Unskilled women were less likely to be physically active in daily life than female professionals.

The probability of practicing habitual physical exercise was higher among men with a normal BMI than among those with severe obesity. The same was true for men with a moderate sense of coherence compared to those with a low score (Table 3). Men who never and/or seldom treated themselves using pharmaceutical products were less likely to do habitual physical exercise than those who frequently used pharmaceutical products.

Physical fitness:

Women with perceived good health were much more likely to be physically fit than women who reported poor health (Table 2). Likewise, women with strong disease-related limitations were less likely to be physically fit than those with little or no limitation. Among the indicators of self-reported health, the probability of high fitness was markedly greater in women with a $\mathrm{BMI} \leq 26$ than in women with a $\mathrm{BMI} \geq 31$. The same was true for women who took no and/or just one medication compared to those who took two or more medications. Women with either a high or a moderate sense of coherence were more likely to be fit than those with a low sense of coherence.

Men with either perceived good or moderate health were more likely to be fit than those with perceived poor health; the $95 \%$ confidence interval included a wide range of positive values (Table 3 ). Men with only one diagnosis in their life-time were more likely to be fit than men with $\geq 2$ diagnoses during their life-time. In terms of healthrelevant attitudes, in men with a moderate external HLC (fate), the probability of fitness was greater than those with a strong HLC. 
Table 1 Distribution of self-reported sport activity, habitual physical activity, and fitness; variables of perceived health; indicators of health-relevant attitudes; and resources in females and males

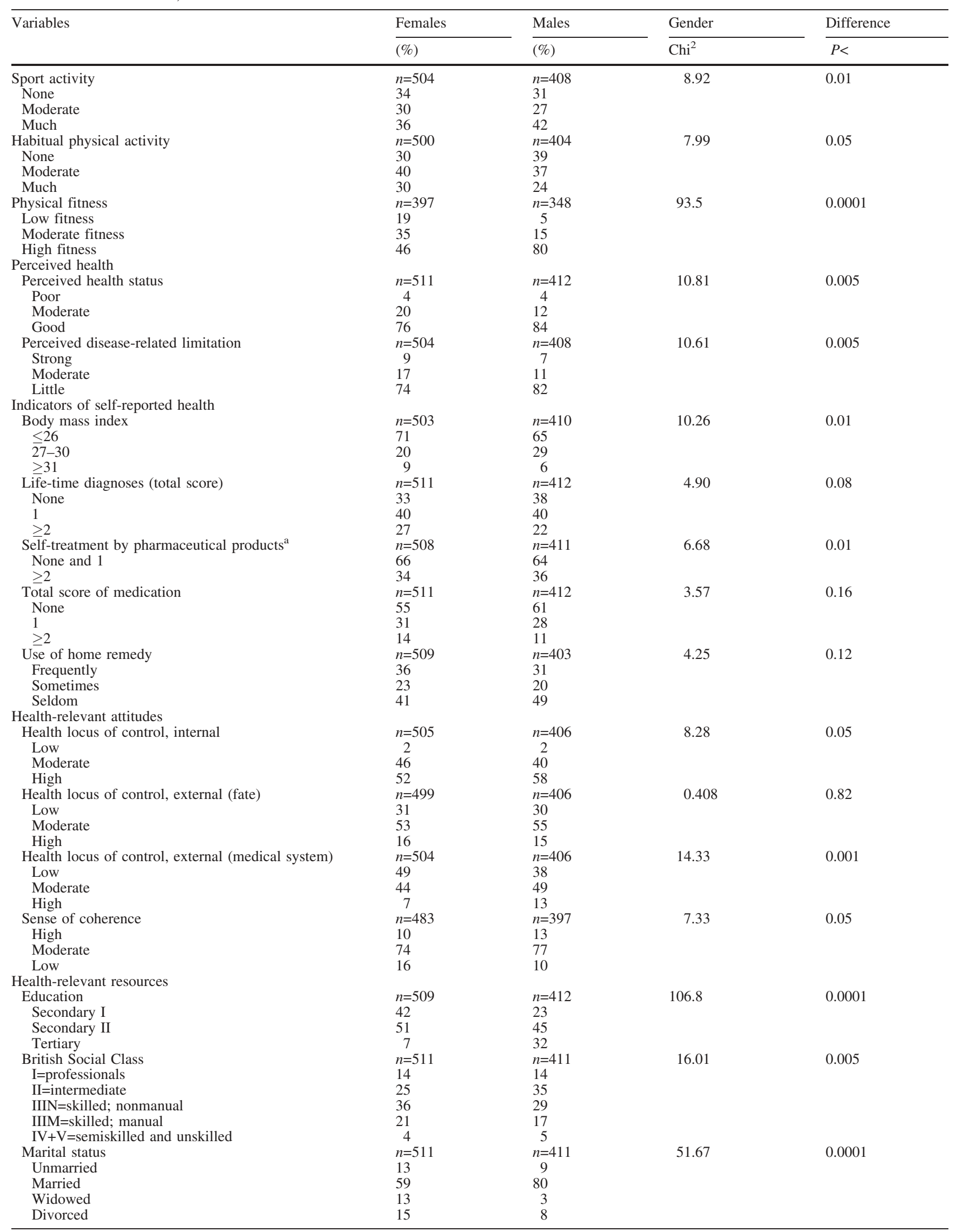

${ }^{a}$ Referred to the last 12 months

$p$ Values are taken from chi square test 
Table 2 Best fit logistic regression of the females' sport activity, habitual physical activity, and fitness as a function of health perception, indicators of self-reported health, healthrelevant attitudes, and resources

\begin{tabular}{|c|c|c|c|}
\hline & Sport activity & Habitual physical activity & Physical fitness \\
\hline Predictor variables & OR $(95 \% \mathrm{CI})$ & OR $(95 \% \mathrm{CI})$ & OR $(95 \% \mathrm{CI})$ \\
\hline \multicolumn{4}{|l|}{ Perceived health status } \\
\hline Good & & $3.09(1.11-8.59$ & $15.28(3.36-64.19$ \\
\hline Moderate & & $2.40(0.81-7.10$ & $1.77(0.45-6.98$ \\
\hline Poor & & 1.0 & 0.0 \\
\hline \multicolumn{4}{|l|}{ Perceived disease-related } \\
\hline \multicolumn{4}{|l|}{ limitation } \\
\hline Strong & & & $0.14(0.05-0.36)$ \\
\hline Moderate & & & $0.73(0.30-1.74)$ \\
\hline Little & & & 1.0 \\
\hline \multicolumn{4}{|l|}{ Body mass index } \\
\hline$\leq 26$ & $2.43(1.24-4.78)$ & & $5.21(1.85-14.68)$ \\
\hline $27-30$ & $1.82(0.86-3.85)$ & & $2.35(0.88-6.25)$ \\
\hline$\geq 31$ & 1.0 & & 1.0 \\
\hline \multicolumn{4}{|l|}{ Total score of medication } \\
\hline None & & & 4.16 1.(70-10.14) \\
\hline 1 & & & $2.80(1.14-6.48)$ \\
\hline$\geq 2$ & & & 1.0 \\
\hline \multicolumn{4}{|l|}{ Use of home remedy } \\
\hline Frequently & $1.70(1.06-2.73)$ & & \\
\hline Sometimes & $1.05(0.65-1.83)$ & & \\
\hline Seldom & 1.0 & & \\
\hline
\end{tabular}

Empty cells refer to variables that have not been included in the model

Table 3 Best fit logistic regression of the males' sport activity, habitual physical activity, and fitness as a function of health perception, indicators of self-reported health, health-relevant attitudes, and resources

\begin{tabular}{|c|c|c|c|}
\hline & Sport activity & Habitual physical activity & Physical fitness \\
\hline Predictor variables & OR $(95 \% \mathrm{CI})$ & OR $(95 \% \mathrm{CI})$ & OR $(95 \% \mathrm{CI})$ \\
\hline \multicolumn{4}{|l|}{ Perceived health status } \\
\hline Good & & & $31.65(7.22-138.63)$ \\
\hline Moderate & & & $8.00(1.63-39.17)$ \\
\hline Poor & & & 1.0 \\
\hline \multicolumn{4}{|l|}{ Body mass index } \\
\hline$\leq 26$ & $2.71(1.19-6.14)$ & $2.50(1.06-5.91)$ & \\
\hline $27-30$ & $2.22(0.93-5.26)$ & $1.77(0.72-4.36)$ & \\
\hline$\geq 31$ & 1.0 & 1.0 & \\
\hline \multicolumn{4}{|c|}{ Life-time diagnoses (total score) } \\
\hline None & & & $3.02(0.67-13.64)$ \\
\hline 1 & & & $4.76(1.12-20.20)$ \\
\hline$\geq 2$ & & & 1.0 \\
\hline \multicolumn{4}{|c|}{ Self-treatment by pharmaceutical products } \\
\hline None and 1 & & $0.46(0.27-0.77)$ & \\
\hline$\geq 2$ & & 1.0 & \\
\hline
\end{tabular}

Empty cells refer to variables that have not been included in the model

\section{Discussion}

In $70 \%$ of Swiss women and $65 \%$ of Swiss men, the dominant determinants of the health concept are "to be physically fit" and "to be free of disease" (Niemann et al. 2000), suggesting that physical activity, fitness, and health are regarded as being linked in people's minds. Theoretically this is an ideal basis for promoting physical activity.

Prevalence of sport activity, and habitual physical activity

The gender-specific differences in the prevalence of sport activity and habitual physical activity in our study (Table 1) are confirmed by previous studies (Abel et al. 2001;
Lamprecht and Stamm 1996, 2000). The differences between women and men might be partly attributable to a historical inequality in women's access to different fields of sport and physical activity (Peyton and Pfister 1989). In this context, it has been suggested that gender as a social and historical phenomenon affects the degree of physical activity. Among women in particular, an underestimation of the amount of muscular activity has to be expected if no distinction is made between regular sport activity and habitual physical activity in daily life (Abel et al. 2001; Bernstein et al. 2001; Weller and Corey 1998).

Women are not less physically active than men but active in a different way, preferring, for example, different types of activity, and lower exercise intensities (Lamprecht and Stamm 1996, 2000; Bernstein et al. 2001; Bodenmann et al. 1990). Habitual physical activity, such 
as daily commuting by bicycle or walking to the shops, is more popular among middle-aged women than men (Table 1). If housework had been considered in the Bern Lifestyle Panel, this type of muscular work could have enhanced the prevalence of moderate and/or much habitual physical activity in the women assessed. According to recommendations on health promotion by exercise (American College of Sports Medicine 2000), 60-70\% of the women and men assessed performed sufficient muscular exercise (Table 1) when self-reported sport activity and habitual physical activity were taken together. Nevertheless, in the remaining 30-40\%, there was a need for greater physical activity (Table 1).

Sport activity, habitual physical activity, and health-relevant associations

In women, low internal HLC seems to reduce, and low external HLC (fate) to increase the frequency of sport activity (Table 2). This implies that women who do not take responsibility for their own health are likely to do less sport than women who do not leave their health to fate. In the Bern Health Report (Weiss 2000) and according to the Swiss Federal Office of Sports et al. (Martin et al. 2000) the more women considered health as a matter of behavior and lifestyle, the more physical activity was prevalent in their lives.

In Switzerland, no sport activity is more prevalent in women with lower socioeconomic status (Bernstein et al. 2001; Gognalons-Nicolet 1997), but health as a motive for sport was shown to be independent of educational level in a representative sample of the population (Lamprecht and Stamm 2000). From the Bern Lifestyle Panel, compared to the highest socioeconomic class, women in the lower socioeconomic classes demonstrated a reduced sport activity (Table 2). A normal BMI and frequent use of a home remedy contributed to a higher frequency of sport activity (Table 2), suggesting that health seems to be a dominant motive for sport activity in the middle-aged urban women assessed. In this context, a normal body weight, use of a home remedy, and sport activity are usually considered as indicators for a health-intentional lifestyle. In men, only the BMI and educational level affect the frequency of doing sport (Table 3), indicating a less differentiated pattern of association compared to women.

Compared to sport activity, habitual physical activity demonstrated different patterns of association with healthrelevant attitudes. Multivariate analyses indicated that perceived good health was the dominant factor contributing to habitual physical activity in the women assessed (Table 2). Additionally, in women, there were greater differences in perceived good health between health-promoting and non-health-promoting attitudes than it did in men (Tables 2 and 3). Women who took little responsibility for their own health and believed it would be maintained or improved little by the medical system were less likely to be physically active in their daily lives than those with high internal and external HLC (Table 2). In contrast, among men, only indicators of self-reported health (BMI, self-treatment with pharmaceutical products) were significantly related to the frequency of habitual physical activity (Table 3). These findings confirm previous results that Swiss women have different motives for physical activity in daily life than Swiss men (Lamprecht and Stamm 1996, 2000). From a theoretical point of view, this is based on a different perception of risk, locus of control, and self-efficiency in women and men, which goes back to gender-specific socialization and roles.

\section{Fitness and health-relevant associations}

Instead of determining physical fitness by exercise testing in the classic way, self-reported fitness was assessed by means of the FFB-Mot questionnaire (Bös et al. 2002). This instrument consists of questions on motor skills, such as endurance, strength, neuromuscular coordination and flexibility (American College of Sports Medicine 2000), which are typically required for daily activities. Self-reported fitness was related to both self-reported and diagnosed health status (Bös et al. 2002; Woll 1996). In the concept of salutogenesis, self-reported fitness is postulated as a resource for an adequate mastery of life (Knoll 1997). Although the prevalence of sport in conjunction with physical activity was similar among women and men (Table 1), more women than men reported having low fitness, and fewer women reported having high fitness, than men. This finding corresponds to a more poorly perceived health and a greater prevalence of self-reported disease-related limitations in women (Tables 2 and 3), and also with their medication intake and BMI (Tables 1 and 2).

The values of perceived health at the lower $95 \%$ confidence interval suggest a high level of confidence in this variable in both women and men. Among the women assessed, the probability of good fitness was associated with a high and/or moderate sense of coherence (Table 2). The association can be explained by the fact that chronic health disorders including menopause-related problems in women are often perceived as a process fluctuating between a reduction in good health and acute disease-related limitations (Gognalons-Nicolet 1997). In this context, Gunzelmann at al. (2000) demonstrated in individuals aged more than 60 years that a higher sense of coherence is associated with a better perceived health and fewer physical complaints than a lower sense of coherence. Among men, the probability of good fitness was associated with moderate external HLC (Table 3), which indicates both self-responsibility and belief in the medical system, in terms of improving and/or maintaining physical fitness.

The important role that the degree of perceived health and disease-related limitations plays in the predictability of habitual physical activity and fitness among women compared with men is an indication that the women under 
study perceive and assess their physical activity and fitness in a more complex way than men. In the cognitive and emotional processes of fitting together individual aspects of activity and fitness, comparison with other women of the same age plays a significant role for their assessment in that these individual aspects are both incorporated and relativized by what women consider to be normal physical activity and fitness (Lamprecht and Stamm 2000). In recording habitual physical activity and individual fitness related to everyday skills, the findings make clear that not only objective health indicators, but also subjective health aspects should be taken into account. This applies to the women in the age group assessed more noticeably than to the men. The individual's perception corresponds to the personal model of reality (Berger and Luckmann1986), which thereby acquires objective significance. This personal model includes norm orientations as well as role understanding and behavior of women and men. As a result, the physical activity and fitness of the genders can be successfully influenced only if the subjective perception and interpretation of health and health-relevant behavior by both genders is taken into account.

Implications for research and practice in public health

This study contributes to exploratory life-style research in the field of public health. Different prevalence in sport and/or habitual physical activity in women and men underline the importance of differentiation between physical activity in sport and in daily life. In women rather than in men, sport activity and habitual physical activity differentiated between indicators of self-reported health, and health promoting and non-health-promoting attitudes. This finding implies that, in using behavioral theory graduated models to change activity behavior, the women assessed could start at a higher level than the men, who show little or no willingness to change their activity behavior within their health-relevant attitudes (Prochaska et al. 1992).

Because of the wide range of sports available nowadays, one can no longer speak of a clear separation between upper-class and lower-class types of sport. However, preferences for particular forms of activity and types of sport in relation to gender and social status are discernible in the present study. These preferences should be taken into account in planning and designing media campaigns and in developing the content of physical activity promotion programs for both genders at different socioeconomic levels.

In the context of the sociocultural embedding of physical activity behavior of men and women, the greater prevalence of sporting activity among men and of habitual everyday activity among the women under study underlines the need for a more differentiated record of physical activity in future research. This applies not only to gender-specific issues but also to any kind of epidemiological study. Alongside recording the type and amount of sporting activity (e.g., walking, cycling), physical activities during everyday work days and leisure time (housework, gardening, climbing stairs, etc.) recommend themselves as categories of activity. This differentiation covers gender-specific sports and physical activity behavior in a more realistic way than the traditional question about the frequency of "sporting activity causing you to break into a sweat" (Swiss Federal Office of Sports 2000). In this way, an underestimation of the amount of physical activity will be avoided or reduced, particularly in the case of women, and there will be a greater probability of discovering an association between the various forms of physical activity and other healthrelevant indicators. The results make plain that, along with indicators of health, attention should be paid to both female and male perceptions of health and self-reported attitudes when there is an attempt to improve physical activity.

\section{Study limitation}

The findings should be judged in light of the quality of the analysis model. A data selection for the regression analysis by means of correspondence analysis is limited by the fact that correspondence analysis is a graphical display method and the results derived from it cannot be statistically guaranteed. In other words, interpretation of the correspondence analysis always leads to a choice of data which, to a certain extent, represents "any old result." This first stage of data selection means that a correspondingly cautious discussion of the findings is necessary, even with subsequent causal-theoretical analysis such as logistical regression.

Women were assigned to the British social class that matched their husbands' professional status. Since more than $30 \%$ of the women assessed were housewives without professional skills, it can be assumed that a major part of the women aged 55-65 have lived traditionally, implying that they either never exercised or exercised only for a short period. A reduced reliability of the association between British Social Class and other variables assessed cannot be excluded.

Since perceived health status, disease-related limitations, and habitual physical activity, among other selfreported variables, are strongly affected by sociocultural and structural influences, it is not possible to draw general conclusions from the findings.

Furthermore, results refer to urban, German-speaking women and men, indicating that there is some limitation in terms of validity for both rural dwellers and people from the French- and Italian-speaking areas of Switzerland where, for example, both women and men were shown to practice sport less regularly than people in German-speaking cantons (Lamprecht and Stamm 2000; Dai et al. 1990). 


\section{References}

Abel T, Karvonen S, Weikunat R (1998) Zur Bedeutung von Wertund Zweckrationalität für gesundheitsrelevanten Sport und körperliche Aktivität: eine explorative Analyse. In: Rütten A (ed) Public Health und Sport. Verlag Stephanie Nagelschmid, Stuttgart, pp 241-255

Abel T, Walter E, Niemann St, Weikunat R (1999) The BerneMunich Lifestyle Panel: background and baseline results from a longitudinal health lifestyle survey. Soz-Präventivmed 44:91106

Abel T, Duetz M, Niemann St (2000a) Statistische Zusammenhänge selbstberichteter Gesundheitsindikatoren: Eine explorative Analyse von Befragungsdaten bei 55-65 Jährigen. In: Bullinger M, Ravens-Siebener U (eds) Lebensqualitätsforschung aus medizinpsychologischer und soziologischer Perspektive. Hogrefe, Göttingen, pp 320-336

Abel T, Kohlmann T, Noack H (2000b) SOC-Fragebogen. Revidierte Fassung der Übersetzung von Noack et al. In: Brähler E, Schumacher J, Strauß B (eds) Diagnostische Verfahren in der Psychotherapie. Hogrefe, Göttingen, pp 326-330

Abel T, Graf N, Niemann St (2001) Gender bias in the assessment of physical activity in population studies. Soz-Präventivmed 46:268-272

American College of Sports Medicine (2001) ACSM's Guidelines for exercise testing and prescription. Lippincott Williams \& Wilkins, Philadelphia

Berger PL, Luckmann T (1986) Die gesellschaftliche Konstruktion der Wirklichkeit. Eine Theorie der Wissenssoziologie. Fischer, Frankfurt

Bernstein MS, Constanza MC, Morabia A (2001) Physical activity of urban adults: a general population survey in Geneva. SozPräventivmed 46:49-59

Bodenmann A, Ackermann-Liebrich U, Ehrsam R, Marti B (1990) Gründe für sportliche Aktivität versus Inaktivität der baselstädtischen Bevölkerung 1988. Soz Präventivmed 35:164-169

Bös K, Abel T, Woll A, Niemann St, Rühl J, Tittlbach S (2002) Der Fragebogen zur Erfassung des motorischen Funktionsstatus (FFB-MOT). Diagnostica 48:101-111

Bury M (1991) The sociology of chronic illness: a review of research and prospects. Sociol Health Illness 13:451-468.

Cockerham WCT, Abel T, Lüschen G, Weber M, (1993) Formal rationality and health lifestyles. Sociol Q 34:413-425

Dai S, Martin B, Rickenbach M, Gutzwiller (1990) Sport korreliert mit günstigen Lebensgewohnheiten: Ergebnisse der Bevölkerungsstudie des Schweizer MONICA-Projekts. Schweiz Z Sportmed 38:71-77

Gognalons-Nicolet M (1997) Geschlecht und Gesundheit (Gender and health). Die Gesundheit von Frauen und Männern in der zweiten Lebenshälfte. Hans Huber, Bern
Gunzelmann T, Schumacher J, Brählker E (2000) Das Kohärenzgefühl bei älteren Menschen: Zusammenhänge mit der subjektiven Gesundheit und körperlichen Beschwerden. ZKPP 48:245-265

Haapanen N, Miilunpalo S, Pasanen M, Oja P, Vuori I (1997) Agreement between questionnaire data and medical records of chronic diseases in middle-aged and elderly Finnish men and women (1997) Am J Epidemiol 145:762-769

Idler E, Benyamin Y (1997) Self-rated health and mortality: A review of twenty-seven community studies. J Health and Social Behavior 38:21-37

Knoll M (1997) Sporttreiben und Gesundheit. -Eine Meta-Analyse. Hofmann, Schorndorf

Lamprecht M, Stamm HP (1996) Age and gender pattern of sports involvement among Swiss labor force. Sociol Sports 31:276287

Lamprecht M, Stamm HP (2000) Sport Schweiz 2000 - Sportaktivität und Sportkonsum in der Schweizer Bevölkerung. Schweizerischer Olympischer Verband, Basel

Lüschen G, Cockerham WC, van der Zee J, Stevens J, Diedericks J, Ferrando MG, d'Hautand A, Peeters R, Abel T, Niemann S (1995) Health systems in the European Union: divergence, convergence, and integration. Oldenbourg, Munich

Martin BW, Lamprecht H, Calmonte R, Raeber PA, Marti B (2000) Swiss Federal Office of Sports, Federal Office of Health, Federal Office of Statistics, Network of Health and exercise (Bundesamt für Sport, Bundesamt für Gesundheit, Bundesamt für Statistik, Netzwerk Gesundheit und Bewegung Schweiz): Körperliche Aktivität in der Schweizer Bevölkerung: Niveau und Zusammenhänge mit der Gesundheit. Schweiz Z Sportmed 48:87-88

McDowell A, Newell C (1996) General health status and quality of life: measuring health. A guide to rating scales and questionnaires. Oxford University Press, New York, pp 380-492

Niemann St, Duetz M, Abel T (2000) Gesundheit: Status und Wahrnehmung-UNIVOX. Gesundheit. Abt. für Gesundheitsforschung, Institut für Sozial- und Präventivmedizin, und Gesellschaft für Sozialforschung, Bern, pp 1-67

Peyton C, Pfister G (1989) Frauensport in Europa. Czwalina, Ahrensburg

Prochaska J, DiCliemente CC, Nocross JC (1992) In search on how people change. Am Psychol 47:1102-1114

Wallston K, Wallston B (1978) Locus of control and health: a review of the literature. Health Educ Monogr 6:107-117

Weiss W (2000) 2. Berner Gesundheitsbericht: Gesundheits- und Fürsorgedirektion des Kantons Bern, pp 39-42

Weller I, Corey P (1998) The impact of excluding non-leisure energy expenditure on the relation between physical activity and mortality in women. Epidemiology 9:632-635

Woll A (1996) Gesundheitsförderung in der Gemeinde. Lingua Med, Neu-Isenburg 